\title{
A LITERATURA COMO DIREITO HUMANO
}

\author{
Carolina Reis Theodoro da Silva ${ }^{1}$ \\ Pedro Pulzatto Peruzzo ${ }^{2}$
}

\begin{abstract}
RESUMO: Este artigo visa abordar a literatura como um direito humano, mostrando seu papel de humanização do indivíduo e de emancipação dos sujeitos, permitindo que o ser humano exista em sua completude. Para tanto, apoiados em estudos de teoria literária e obras de literatura, em especial a obra de Antonio Candido, analisaremos as esferas de atuação da literatura nos indivíduos. Primeiramente, abordaremos a esfera pessoal, em decorrência de seu caráter humanizador, em segundo, a esfera psicológica, já adentrando o papel de sublimação das pulsões da literatura e, por fim, a esfera social, evidenciando seu caráter emancipatório. Finalmente, desenvolveremos a relação do direito à literatura com o direito à educação e o direito à cultura. Buscaremos, portanto, mostrar que a literatura é essencial para que se viva de forma digna e completa, justamente por conferir ao ser humano uma parcela de sua humanidade, sendo-lhe inegável o título de direito humano.
\end{abstract}

Palavras-Chave: direito; literatura; humanização; direitos humanos; direito à literatura.

\section{INTRODUÇÃO}

O presente $\operatorname{artigo}^{3}$ tem como objetivo demonstrar que a literatura é um direito humano. Para sustentar essa hipótese, recorremos a obras literárias, de teoria literária e documentos jurídicos nacionais e

1 Bacharela em Direito pela Pontifícia Universidade Católica de Campinas (PUCCampinas). Bacharela em Letras pela Universidade Estadual de Campinas (UNICAMP). Campinas (SP), Brasil. ORCID: https://orcid.org/0000-0002-5803-4938. CV Lattes: http://lattes.cnpq.br/4918195683650395. E-mail: carolina.reistheodoro@gmail.com

2 Doutor e Mestre em Direito pela Universidade de São Paulo (USP). Professor Titular Categoria A1 da Pontifícia Universidade Católica de Campinas (PUC-Campinas). Professor do Programa de Pós-Graduação em Direito da PUC-Campinas. Membro do grupo de pesquisa Direito num mundo globalizado (DGP/CNPq). Campinas (SP), Brasil. ORCID: $\quad$ http://orcid.org/0000-0001-5270-8674. CV Lattes: http://lattes.cnpq.br/5126921195345108. E-mail: peruzzopp@hotmail.com

3 Agradecemos imensamente aos avaliadores pelas valiosas sugestões e críticas. Todos os comentários foram fundamentais para o aprimoramento do texto. 
internacionais. Assim sendo, o método utilizado para o desenvolvimento deste trabalho foi de análise documental com revisão bibliográfica e legislativa.

Fábio Konder Comparato (1997) esclarece, em referência a Bobbio, a grande dificuldade de se conceituar direitos humanos e sugere que esse conjunto de direitos deve ser definido pelo seu objetivo. Nessa linha, afirma que se o direito é uma criação humana, o seu valor deriva, justamente, daquele que o criou, o próprio homem, considerado em sua dignidade substancial de pessoa, diante da qual as especificações individuais e grupais serão sempre secundárias.

Ocorre que, para se pensar em direitos humanos, é fundamental refletirmos acerca de um pressuposto, que, para Antonio Candido ${ }^{4}$, no capítulo Direito à literatura ${ }^{5}$ de sua obra Vários escritos (1995, p. 254), é: "reconhecer que aquilo que consideramos indispensável para nós é também indispensável para o próximo.” Para ele, é comum pensarmos que todos têm direito a certos bens fundamentais, como moradia, educação e comida, mas raramente estendemos todos os nossos direitos ao próximo.

Assim, muitos acreditam que todos os indivíduos têm direito à educação e à alimentação, mas que não teriam direito a ler Dostoiévski, por exemplo - apesar de eles mesmos poderem desfrutar desse direito. Esse fato é explicado em razão de a luta pelos direitos humanos ser considerada uma batalha pelo possível, e não pelo desejável, já que nem sempre é possível haver proteção a esses direitos onde ela é mais necessária, e, onde tal possibilidade de proteção existe, ela talvez não seja tão necessária (Fachin, 2017, p. 160).

Surge, portanto, a questão: seria a literatura um direito humano? Para respondermos a essa pergunta, é fundamental entendermos seu papel na vida do ser humano. Afinal, seria a literatura um direito inerente à nossa condição humana? Algo essencial para que se viva de forma digna e completa? São essas as perguntas que norteiam o presente trabalho, que buscam mostrar que a literatura de fato atua no caráter e na construção dos

4 Antonio Candido foi um crítico literário, sociólogo, ensaísta e professor brasileiro. Sua extensa obra crítica é respeitada pelas principais universidades do país.

5 Destaca-se que a leitura desse capítulo foi ponto de partida para o presente trabalho, e, portanto, encontramos amparo em suas ideias. Sugerimos sua leitura a quem quiser se aprofundar ainda mais no tema. 
sujeitos sociais, justamente por ter um papel formador e transformador da personalidade, da própria emancipação dos sujeitos. Isso, pois, como veremos, o texto literário atua diretamente no indivíduo leitor, afetando suas esferas pessoal, psicológica e social.

Como se sabe, apesar de os direitos humanos terem eficácia horizontal, ou seja, valerem também nas relações privadas, o processo histórico de afirmação desses direitos teve origem na necessidade de construir círculos protetivos da dignidade humana contra a ação estatal e contra as maiorias ${ }^{6}$. Ou seja, os direitos humanos normalmente se destinam à proteção das múltiplas dimensões do ser humano contra interferências injustificadas do Estado em suas esferas individuais ou coletivas. Pensar o direito humano à literatura, portanto, exige de nós o esclarecimento sobre qual dimensão humana esse direito protege e, do mesmo modo, em que medida o Estado tem atingido negativamente essa esfera.

Neste texto trabalhamos a literatura como meio de acesso à arte, numa perspectiva de acesso à cultura e à educação, mas também nos preocupamos em registrar que a literatura, na mesma medida em que proporciona experiências culturais e educacionais7 dessa natureza, também funciona como instrumento de refinamento da sensibilidade e, por isso mesmo, de humanização, de constituição do ser humano como sujeito. Esse processo, vale registrar, não ocorre apenas na educação formal, mas também na educação não-formal. A título de exemplo, o Plano Nacional de Educação em Direitos Humanos ${ }^{8}$ explica que a educação não-formal em direitos humanos orienta-se pelos princípios da emancipação e da autonomia e sua implementação configura um permanente processo de sensibilização e formação de consciência crítica, direcionada para o encaminhamento de reivindicações e a formulação de propostas para as políticas públicas.

6 Mais concretamente, a ideia constitucional dos direitos fundamentais afirmou-se para proteção dos cidadãos, não só contra o Executivo monárquico (para isso bastaria a legalidade administrativa), mas contra as próprias maiorias parlamentares, que deveriam respeitar valores tão importantes como o estatuto fundamental dos indivíduos na sociedade política (Andrade, 2001, p. 199).

7 A Lei de Diretrizes e Bases da Educação Nacional determina que o estudo de artes é obrigatório (artigos 26, parágrafo $1^{\circ}$, e $35^{-A}$, parágrafo $2^{\circ}$ ).

8 Cf. Plano Nacional de Educação em Direitos Humanos (Brasil, 2007). 
Assim, reforçando que estamos propondo uma reflexão sobre a literatura como meio de acesso à cultura, à educação, e como experiência de sensibilidade, entendemos importante registrar, apenas para delimitar melhor nossa proposta, que o fato de não estarmos trabalhando outras experiências culturais, educacionais e artísticas, como o teatro e, inclusive, a física, não significa que desprezamos a relevância dessas expressões na formação crítica da subjetividade.

Considerando o atual estado de emparelhamento dos órgãos formuladores de políticas públicas de educação e cultura por uma ideologia que vê a sensibilidade artística e o pensamento crítico como um problema que deve ser evitado 9 , trabalhar a literatura como um direito humano e, por isso mesmo, como círculo protetivo das dimensões humanas constituintes de uma dignidade que só pode emergir da emancipação, justifica o presente trabalho e esclarece o esforço que fizemos para desenvolver o nosso objeto e validar nossa hipótese.

Iniciaremos este trabalho buscando fixar um parâmetro do que estamos entendendo por literatura. Em seguida analisaremos as esferas de atuação da literatura no indivíduo. Também analisaremos a literatura como instrumento de sublimação das pulsões. Por fim, trataremos a literatura e seu papel transformador da sociedade a partir das representações sociais, mostrando sua relevância também para a humanização do jurista. Finalmente, será desenvolvida a relação do direito à literatura com o direito à educação e o direito à cultura, a partir de uma análise de documentos de direito internacional e nacional.

Buscaremos, dessa forma, explicitar a essencialidade da literatura para a transformação do ser humano em sua totalidade e sua importância para que viva dignamente, sendo, assim, direito humano e, por isso, direito de todos. Afinal de contas, "assim como não é possível haver equilíbrio

9 A esse respeito podemos citar a extinção do Ministério da Cultura pelo governo de Jair Messias Bolsonaro e a proposta de censurar a obra de Paulo Freire na educação pública (Saldaña, 2019). Além disso, existem inúmeras ações em curso que ainda não se concretizaram, mas que apontam para um cenário de intensificação do esvaziamento da pauta cultural no Estado brasileiro (Nunomura, 2019). Esse cenário não toma apenas o governo federal, valendo registrar que o governador do Rio de Janeiro, Wilson Witzel, também fechou exposição um dia antes do previsto e proibiu uma performance que faria referência à tortura na ditadura militar na Casa França-Brasil. 
psíquico sem sonho durante o sono, talvez não haja equilíbrio social sem a literatura" (Candido, 1995, p. 256).

\section{O QUE É LITERATURA E QUAL SUA RELAÇÃO COM A SOCIEDADE}

Primeiramente, é fundamental restringir o que estamos entendendo por literatura. Ressaltamos que a tentativa de definição da literatura é uma discussão muito antiga dentro da teoria literária, afinal, não se trata de algo objetivo, mas subjetivo, que traz consigo uma carga valorativa no momento de sua construção e interpretação. Destacamos, ainda, que nosso objetivo não é exaurir a discussão sobre o conceito de literatura, mas sim trazer elementos suficientes para delimitar minimamente o objeto para passarmos à discussão desta como um direito humano.

De início, vale ressaltar que literatura não é só o que é escrito. A matéria-prima da literatura não é só a linguagem escrita, mas também a linguagem oral. Na realidade, foi através da tradição oral que a literatura teve seu início, quer porque a escrita ainda não era tão comumente utilizada ou porque sequer existia escrita. Para ilustrar, podemos citar Homero como exemplo, uma vez que suas histórias são apontadas por estudiosos como um compilado de contos tradicionalmente orais, além das manifestações culturais de povos indígenas que continuam transmitindo suas histórias literárias através da oralidade.

Além disso, outro elemento comum de definição é o de que a literatura nada mais é do que uma expressão artística que organiza o mundo e os sentimentos humanos, utilizando-se de estruturas linguísticas para tal. No entanto, muitas das estruturas e conteúdo de uma obra literária só podem ser compreendidos a partir do momento em que enxergamos seu contexto histórico produtivo, pois o que antes poderia parecer rude e sem sentido acaba sendo axiologicamente ressignificado, ganhando seu espaço. É o que ocorre, por exemplo, com os poemas modernistas de Manuel Bandeira, aparentemente simples e sem valor literário.

Em razão disso, podemos tentar dar diversas definições à literatura, baseadas na forma, circularidade, simetria, economia de forma, falta de economia de forma e repetição. Ou ainda baseadas na complexidade psicológica do humano, equilíbrio e harmonia psicológicos, bem como desequilíbrio e desarmonia psicológicos. 
Por fim, vale registrar as definições apoiadas na diferença epistemológica entre literatura e outras formas de expressão, como o conhecimento científico. Afinal, a literatura não tem a obrigação de dizer a verdade do que ocorre com o mundo, pois existe espaço suficiente para tratar da ficção em sua forma pura, para tratar de referenciais sociais e para tratar da ficção referencial (Fry, 2012), acolhendo tanto a sanidade como a loucura, para além das convenções que, normalmente, criminalizam ou estigmatizam a segunda.

Desse modo, entendemos que a pergunta certa a se fazer não é "o que é literatura? ", mas sim "quem define o que é literatura? ". E isso faz todo o sentido para o objetivo de incluir a literatura no rol dos direitos humanos.

Por muito tempo, a literatura representou a visão de mundo das pessoas que tinham acesso a livros (que por muito tempo foi exclusivo das elites), pois, através de sua própria subjetividade, definiam quais textos eram de fato literários. Claro, se um professor doutor especializado em literatura diz que determinada obra é literária e outra não, em razão de seu prestígio intelectual e social dentro da sociedade, aquilo provavelmente será mais aceito como verdade, pois sua voz terá mais autoridade - trata-se de uma instância de legitimação.

Em seu livro Teoria da literatura - uma introdução, Terry Eagleton aceita o desafio de tentar definir o que é literatura e nos mostra que:

Considera-se que a literatura contenha muitas outras coisas além da poesia - por exemplo, obras realistas ou naturalistas que não são linguisticamente autoconscientes nem constituem uma realização particular em si mesmas. [...] A "literatura" pode ser tanto uma questão daquilo que as pessoas fazem com a escrita como daquilo que a escrita faz com as pessoas (2006, p. 9-10, grifamos).

Logo, definir a literatura é algo extremamente complexo e impossível de se fazer em escala universal, justamente em razão de a literatura de um povo ser tudo aquilo que seus referenciais culturais e sua comunidade interpretativa dizem ser. Portanto, entender a literatura é enxergar o que causa a literatura e suas consequências. Essas últimas são, em destaque, a criação de um autor que sente e se comunica e de um leitor que se comunica e sente. Dessa forma, vemos que a literatura só existe a partir dos juízos de valor históricos de seu contexto produtivo e de seu contexto 
interpretativo/apreciativo, mas que esses juízos são extremamente variáveis.

Vimos que a definição objetiva de literatura não é possível; no entanto, podemos delimitar minimamente aquilo a que as pessoas devem ter acesso por ser um direito humano. Logo, vemos que não estamos nos referindo apenas ao cânone literário, a obras clássicas e eruditas, mas também à literatura marginalizada, aos best-sellers, à literatura de cordel, à literatura oralizada e tantas outras manifestações artísticas que, aderindo ou não às convenções, expressam infinitas possibilidades de sermos humanos a partir das visões de mundo de grupos e indivíduos cultural ou socialmente diferenciados. Afinal, o que importa pode não ser a origem do texto, mas o modo pelo qual as pessoas o consideram: "Se elas decidirem que se trata de literatura, então, ao que parece, o texto será literatura, a despeito do que o seu autor tenha pensado" (Eagleton, 2006, p. 13).

Exemplo recente disso ocorreu na Universidade Estadual de Campinas (UNICAMP), que inseriu em sua lista de obras obrigatórias para o vestibular de 2020 o álbum "Sobrevivendo no inferno", do grupo de rap Racionais MC's. Os candidatos deverão ler algumas obras de diferentes gêneros - poesia, conto, romance, teatro, crônicas e sermões - e, dentre elas, as letras das 12 músicas que compõem o álbum e que integram a categoria "poesia" dessa lista. Afinal, o acesso deve ser total; não é porque determinado indivíduo vive marginalizado que não poderá universalizar a literatura periférica ou acessar a literatura produzida nos centros de hegemonia. A literatura deve ser acessada por todos de forma irrestrita por ser direito humano que amplia as possibilidades de formação de sujeitos.

Nessa linha, todos devem ter direito ao preparo e às ferramentas para acessá-la, pois, como veremos mais adiante, mais do que disponibilidade, é importante que sejam garantidas as condições de acesso. Desse modo, o intercâmbio literário cultural entre as diferentes perspectivas sociais pode levar a compreender melhor as nuances das diferenças que marcam a humanidade.

\section{A LITERATURA COMO FATOR DE HUMANIZAÇÃO}

O estímulo à leitura de textos literários resulta em uma educação estética plural da humanidade, pois a literatura acaba por atuar no 
consciente e no inconsciente do leitor, provocando seus impulsos, harmonizando sua natureza e sua cultura e, assim, contribuindo para suscitar experiências que dizem respeito à totalidade do humano.

A literatura traz em si um fator humanizador que vai muito além da pura expressão artística ou do ser, pois, além de ser muito desperta no seu enunciador, desperta também no receptor a percepção de uma visão de mundo mais ampla, transbordando até em visões de mundos diferentes. Mas o que de fato se entende por humanização? Para tanto, nos apoiamos na definição de Antonio Candido (1995, p. 254):

Entendo aqui por humanização (já que tenho falado tanto nela) o processo que confirma no homem aqueles traços que reputamos essenciais, como o exercício da reflexão, a aquisição do saber, a boa disposição para com o próximo, o afinamento das emoções, a capacidade de penetrar nos problemas da vida, o senso da beleza, a percepção da complexidade do mundo e dos seres, o cultivo do humor. A literatura desenvolve em nós a quota de humanidade na medida em que nos torna mais compreensivos e abertos para a natureza, a sociedade, o semelhante.

O contato com textos literários, portanto, tem o potencial de despertar nos leitores novas visões de mundo e novas percepções a respeito de si mesmos. Entrar em contato com outras visões de mundo nos leva a questionar, ressignificar e refletir a respeito de nossas próprias visões, de nossos valores e de nossas convicções. A literatura permite um intercâmbio cultural, geracional e social que desperta a multiplicidade de cada ser. Nunca é demais lembrar da potência revolucionária do Quarto de despejo de Carolina Maria de Jesus.

No entanto, atualmente, temos assistido a expulsão da arte da vida do ser humano, pois "a indústria cultural impõe o entretenimento que visa à distração, e não à formação do indivíduo, e desvia o ser humano do perigo que representaria a literatura enquanto estímulo à reflexão" (Moraes, 2010, p. 4). A arte - que tem o condão de informar, entreter, revolucionar, incomodar e distrair - acabou por se dissipar atualmente como elemento de pura distração. Em outros termos, a indústria cultural impõe algumas formas de entretenimento que, ao invés de informar e suscitar a reflexão, acaba proporcionando apenas a distração alienada, voltada apenas ao consumo, e não à formação do indivíduo, seja pelo ócio, pelo lazer ou pela reflexão crítica. Desse modo, a cultura de massa acaba por estimular o 
consumo mascarado de entretenimento, sendo possível comprovar isso com os influenciadores digitais ${ }^{10}$.

Theodor Adorno, em Indústria cultural e sociedade, apresenta o termo "indústria cultural" e o diferencia da "cultura de massa", sendo esta oriunda de um povo, de suas regionalizações e costumes, sem a intenção de ser uma cultura comercializada como mercadoria; ao passo que aquela é construída a partir de padrões que se repetem buscando formar uma estética comum que se volta necessariamente ao consumismo e ao controle dos corpos e não à sua emancipação - de servir-se de seu entendimento sem a orientação de um outro (Kant, 1985).

Para Adorno (2002), a sensação de felicidade e satisfação promovida pela indústria cultural desmonta qualquer mobilização crítica e não permite a formação de uma autonomia consciente. No Brasil, por exemplo, acaba sendo mais comum uma pessoa dedicar seu tempo livre às redes sociais, shows de stand up comedy e programas de televisão do que à leitura de textos literários, seja por falta de incentivo, falta de acesso, ou até por considerar essa atividade tediosa em comparação à dinâmica de movimento das demais atividades a que está acostumada.

Assim, ler literatura é ousar saber, Sapere aude! (Kant, 1985). E mais, é produzir sentidos a partir de contextos histórico-sociais delimitados por seu enunciador, e o contato com tal contexto permite o intercâmbio de culturas, crenças, valores, costumes e paradigmas. O choque dessas realidades permite reconhecer as semelhanças e identificar as diferenças entre os sujeitos (autor, leitor e personagens), permitindo uma reflexão acerca do novo ou do velho. Isso significa que, a partir desse exercício, adentramos o território da ética da alteridade, que nos ajuda a "ver no outro um ser merecedor de igual consideração e profundo respeito, orientada pela afirmação universal da dignidade e pela prevenção do sofrimento humano" (Fachin, 2017, p. 161). Através da concretude do outro, manifestada na literatura, o leitor compreende sua própria história, e mais, pois, ao realizar

10 Influenciadores digitais são pessoas que se popularizam em redes sociais, como Instagram, Youtube, Facebook, Twitter, dentre outras, gerando conteúdo para um público massivo que acompanha e consome suas publicações, guiando decisões de consumo e tendência. 
o exercício da alteridade, converte-se em personagem e compreende melhor o próximo.

Nesse aspecto, a literatura como fator humanizador é de suma importância na educação do ser humano, desde a infância, para que cresçamos habituados a estabelecer tal reflexão. Em outros termos, além de um direito humano, ao promover a ética da alteridade a literatura é um direito da e para a própria humanidade.

Ao ler literatura e escrever a partir dela, o estudante
aprenderá a ler e escrever a existência humana,
atribuindo-lhe sentido, reconhecendo-lhe conteúdo e
forma individual. Ela manifesta, através de cada escritor,
em cada obra ou em cada ato de leitura, múltiplas
significações e diversas ordens de significados, mas,
acima de tudo, possui uma supersignificação, que se refaz
a cada leitura. E não é estática; está em permanente
desenvolvimento, no tempo e/ou no espaço (Filipouski,
2005, p. 225).

Ressaltamos, no entanto, que não basta apenas ter acesso ao texto literário por si só, pois, caso o sujeito não tenha tido acesso a um processo de alfabetização, a literatura não será capaz de, sozinha, desenvolver seu papel. Portanto, é primordial que haja também acesso irrestrito à alfabetização, como estabelece a Constituição Federal em seu artigo 214:

A lei estabelecerá o plano nacional de educação, de duração decenal, com o objetivo de articular o sistema nacional de educação em regime de colaboração e definir diretrizes, objetivos, metas e estratégias de implementação para assegurar a manutenção e desenvolvimento do ensino em seus diversos níveis, etapas e modalidades por meio de ações integradas dos poderes públicos das diferentes esferas federativas que conduzam a:

I - erradicação do analfabetismo;

Além disso, destacamos o compromisso firmado pelo Estado brasileiro de facilitar o acesso a obras publicadas àquelas pessoas que precisam de certa adaptação em razão de alguma deficiência, ao promulgar, pelo Decreto 9.522 de 2018, o Tratado de Marraqueche para facilitar o acesso a obras publicadas às pessoas cegas, com deficiência visual ou com outras dificuldades para ter acesso ao texto impresso. Afinal de contas, a literatura é feita pelo homem para o homem. Conforme Mario Vargas Llosa (apud Moraes, 2010, p. 5):

A melhor contribuição da literatura ao progresso humano [seria] recordar-se (involuntariamente, na maior parte dos casos) de que o mundo se acha mal-acabado, de que 
mentem os que sustentam o contrário - por exemplo, os poderes que o governam -, e de que poderia ser melhor, mais próximo dos mundos que a nossa imaginação e a nossa palavra são capazes de inventar.

Concluímos, por ora, que a literatura é uma necessidade humana, justamente por permitir a reflexão acerca de si mesmo, do outro e da sociedade como um todo. Reside aqui a importância de tratá-la como um direito humano, por permitir que o ser humano viva uma vida mais digna e completa

\section{A ESFERA PSICOLÓGICA E A ESFERA SOCIAL}

Além de ser um instrumento de humanização pela ética da alteridade e pela compreensão de si no mundo, a arte também é relevante para a psicanálise como forma de sublimar a pulsão. Para entendermos melhor, é necessário definirmos o que a psicanálise entende por pulsão, também sem a pretensão de esgotar o tema, considerando nosso objeto e nossa própria formação.

Para Sigmund Freud, a pulsão é algo que move o ser humano, evitando que este fique estanque, fazendo-o agir ininterruptamente, sendo, pois, uma força interna do psiquismo humano que busca constantemente a satisfação. Todos carregam dentro de si pulsões de vida e de morte, sendo que as primeiras se identificam com a capacidade de criar, ou seja, é a capacidade de projetar a forma subjetiva e singular de ser no mundo e a segunda diz respeito à possibilidade destrutiva inerente ao homem (Figueiredo; Feitoza; Carvalho, 2012).

Uma forma de lidar com essas pulsões é através da sublimação, que nada mais é do que um dos destinos da pulsão por gerar um processo de desvio das forças pulsionais. As atividades sublimatórias englobam atividades artísticas, intelectuais e esportivas; afinal, a ideia de sublimar remete à ideia de ascensão, verticalidade e transcendência e, para tanto, é primordial que haja uma válvula de escape externa para tais pulsões Mendes, 2011).

Importante destacar que a sublimação pode se dar em duas direções, seja considerando o aspecto da criação ou da defesa contra o sexual. No primeiro caso, sendo uma energia que se volta para as realizações culturais, a sublimação propicia um trabalho analítico da criação, ou seja, a arte é 
capaz de incentivar a sublimação de uma pulsão individual, externando-a de uma maneira que permita compreendê-la e transcendê-la. Assim, ao sublimar determinadas pulsões, o indivíduo passa a (re)conhecer um pouco mais sobre si mesmo, evitando que tais pulsões se manifestem de maneira prejudicial ao seu psiquismo.

É importante abordar que os processos civilizatórios
acabam reprimindo, restringindo as pulsões e
acarretando diversos sofrimentos psíquicos, porém, por
outro lado, surge a sublimação como um espaço de cura e
fator primordial nos processos culturais. Pois, a
sublimação e a erotização visam dominar a pulsão de
morte nas pulsões de vida, tornando a vida possível para
o sujeito (Figueiredo; Feitoza; Carvalho, 2012, p. 55).

Na literatura, a sublimação pode ocorrer no ato da criação artística, na pessoa do sujeito-autor, como também no ato de fruição da arte, na pessoa do sujeito-leitor. A partir disso, a distância real mesclada com a proximidade promovida pela arte possibilita a tolerância da coexistência com o próximo, sendo de extrema relevância para a convivência com as diferenças e sensibilização e respeito para a alteridade - tema que veremos a seguir.

Toda forma de arte, em especial a literatura, carrega consigo ideias e imagens de representações coletivas e/ou individuais. $\mathrm{O}$ autor de uma obra literária diz muito sobre si mesmo e sobre seu contexto social a partir de suas palavras e até mesmo da ausência delas. Assim, o leitor de tal obra é capaz de captar a mensagem que o autor quer passar e, inclusive, aquela que ele nem ao menos intencionava, pois a obra lida passa a ser uma ideia concretizada na realidade também do leitor. Além disso, não existe apenas uma leitura da obra, mas sim diferentes olhares decorrentes de leituras e releituras de diferentes leitores e até de um mesmo leitor, evidenciando que uma leitura em específico é apenas um olhar dentre muitos (Fachin, 2017, p. 155). Ao fazer esse exercício de interpretação e troca de significados, o leitor chega às suas próprias conclusões, que podem vir a formar sua própria identidade, afinal, “a identidade não se constrói racional e objetivamente, mas é resultante de um processo histórico ou de práticas sociais que se traduzem em representações” (Pesavento, 1995. p. 121).

A fixação de um padrão identitário advém de representações sociais, pois exprimem em si mesmas padrões históricos, culturais e sociais. Desse modo, ao entrar em contato com tais representações - o que pode se dar 
através da arte -, o indivíduo pode ser levado a uma tensão e a um conflito, o que garantiria oportunidades de questionar os padrões impostos pela condição familiar, social ou política em que ele está inserido, seja para aceitá-los, desconstruí-los ou reconstruí-los; oportunidades que levariam ao questionamento de padrões representativos dominantes, e até à possível quebra de relações de poder preestabelecidas.

Mas o que seriam de fato estas representações sociais? É claro que elas são variáveis e diretamente ligadas com a cultura e sociedade do momento de sua construção. Podem ser universais, mas não o são necessariamente, e podem se prolongar no tempo. Para uma definição, podemos dizer que:

\begin{abstract}
Representações sociais são sistemas de valores, ideias e práticas que permitem a comunicação entre membros de uma comunidade a partir de um código para intercâmbio social e outro para nomear e classificar de maneira inequívoca os vários aspectos de mundo e de suas histórias como indivíduos e como um grupo (Moscovici apud Howarth, 2006, p. 80, tradução livre).
\end{abstract}

Vemos que um sujeito, a partir de sua própria vivência e expressão de sua individualidade, além da identificação com outros sujeitos, pode construir uma representação, e essa representação acaba sendo uma expressão do próprio sujeito.

$\mathrm{Na}$ literatura brasileira, podemos verificar tal fenômeno na obra de Manuel Antônio de Almeida, Memórias de um sargento de milícias, pois o autor utiliza de seu personagem Leonardinho para abordar a figura do malandro urbano, figura característica do malandro carioca de 1853. A identidade brasileira da malandragem, do "jeitinho brasileiro", partiu de um grupo social delimitado (os malandros cariocas) e fez-se representar na figura de Leonardinho. Depois, ultrapassou o texto literário e se tornou expressão da representação social nacional (Pesavento, 1995, p. 119).

Importante destacar que a literatura não atua apenas na criação de figuras identitárias, mas também na criação de figuras estigmatizantes. Citando o mesmo exemplo literário, de Almeida, o "jeitinho brasileiro" ora é visto por nós brasileiros como algo positivo, algo a se orgulhar, dependendo do contexto e da situação em que é empregado, ora é visto com vergonha, como depreciativo da nossa sociedade. O "jeitinho brasileiro" como "feito 
de qualquer jeito" já carrega em si características estigmatizantes, por ser como uma mancha infamante e imoral na reputação do brasileiro.

A esse respeito, citamos ainda a obra de Mário de Andrade, Macunaíma, que traz uma rapsódia sobre a formação do Brasil, unindo múltiplas características nacionais para criar uma identidade brasileira, fazendo nascer, por fim, a figura de Macunaíma, índio preguiçoso, que até os seis anos não falava por pura preguiça, e cuja sexualidade é quase animalesca, por ter a necessidade e a ânsia de "brincar" com personagens em diversas partes da história.

Além disso, ao entrar em contato com a literatura e as infinitas possibilidades das obras literárias (ficcionais ou não), o leitor, a partir do choque de mundos, ideias e paradigmas, passa a ter subsídios para realizar uma autoinvestigação acerca do seu lugar no mundo, o que pode levá-lo a pensar e inclusive agir de forma diferente. Esse contato com o diferente pode gerar uma sensibilização para a alteridade, como mencionamos anteriormente.

Já na literatura universal, podemos ver, através da obra Os miseráveis, de Victor Hugo, a desconstrução da representação social do pobre, do miserável, justamente por abordá-lo de uma maneira nunca antes vista na literatura, conferindo-lhe uma nova identidade. Victor Hugo cria um romance cujos personagens centrais são pobres, dando voz aos preconceitos e injustiças sofridos, além de sofrimento, paixões, dor, luta, orgulho, esperança, fome, desemprego, entre outros, fazendo um retrato da sociedade francesa do século XIX, explicitando a miséria e o sofrimento de sua população. Assim, o autor desmistifica o estigma de periculosidade desses sujeitos sociais, possibilitando novas visões a respeito deles.

O contato do leitor da obra literária com representações de si próprio ou do outro impulsiona seu crescimento pessoal, ecoando no seu papel dentro da sociedade. Além disso, o contato com a representação através da literatura traz a possibilidade de que paradigmas sejam contestados, negados e transformados; e, através do reconhecimento de representações, podemos assumir nossos papéis dentro da sociedade, reivindicar identidades que nos são negadas e nos defender de estigmas e práticas marginalizantes (Howarth, 2006). Isso, pois, como ensina Pesavento (1995, p. 116): "Tomemos como pressuposto que a representação envolve uma 
relação ambígua entre ausência e presença. No caso, a representação é a presentificação de um ausente, que é dada a ver por uma imagem mental ou visual que, por sua vez, suporta imagem discursiva”.

Portanto, a leitura de textos literários permite a aproximação com novas visões de mundo e diferentes sujeitos, propiciando um novo olhar sobre a marginalização de determinadas representações sociais. Ocorre, que, ao entrar em contato com o diferente, acabamos por nos chocar com aquilo que pode vir a nos causar estranhamento. Para Freud (1917), o que é estranho pode ser definido, de uma maneira resumida, como aquilo que desperta o medo em geral; isso, pois, o estranho é aquilo que é alheio à nossa esfera de sentido, isto é, alheio ao nosso núcleo especial de sensibilidade.

Segundo Freud, "o estranho seria sempre algo que não se sabe como abordar" (1917, p. 139). Na literatura, o psicanalista austríaco afirma que o autor de uma obra literária consegue abordar as representações do outro de forma que sejam ou não estranhas ao leitor. Isso pode se dar a partir de diferentes gêneros, inclusive da fantasia, fazendo com que o leitor tenha sua esfera do que lhe é comum e aceitável abalada, por ter um vislumbre desse estranhamento.

O escritor imaginativo tem, entre muitas outras, a liberdade de poder escolher o seu mundo de representação, de modo que este possa ou coincidir com as realidades que nos são familiares, ou afastar-se delas o quanto quiser. Nós aceitamos as suas regras em qualquer dos casos. Nos contos de fadas, por exemplo, o mundo da realidade é deixado de lado desde o princípio, e o sistema animista de crenças é francamente adotado.[...] Assim, verificamos que as histórias de fadas, que nos proporcionaram a maioria das contradições em relação à nossa hipótese de estranho, confirmam a primeira parte da nossa proposta - de que, no domínio da ficção, muitas dentre as coisas que não são estranhas o seriam se acontecessem na vida real (Freud, 1917, p. 158)

Desse modo, a literatura consegue, através de suas representações sociais e alegorias fantásticas ou fantasiosas, transcender a realidade e criar situações que proporcionam o estranhamento no leitor e que provocam o contato com o diferente. Trata-se, destarte, da presentificação do ausente, com o consequente estranhamento e a possível sensibilização para a alteridade. 
Podemos dizer que o mundo externo ao leitor não é de fato apenas externo, já que esse mundo externo é elemento constitutivo do interior do leitor, culminando na construção de seu mundo externo imediato. Assim, a experiência da alteridade, decorrente do fenômeno do estranhamento, permite o contato com o mundo externo do outro, possibilitando não só seu reconhecimento, mas também o reconhecimento e/ou a ressignificação de seu próprio eu.

É em razão disso que vemos a importância da arte, em especial da literatura, não por apenas projetar imagens positivadas da realidade, "mas, pelo contrário, negando-a de dentro, evidenciar suas fissuras - criando buracos, projetando sombras, construindo perspectivas outras em que o permanente, o não contraditório e harmônico deem lugar ao conflito, à vertigem, ao não-idêntico" (Nunes, 2013, p. 8)

A arte literária carrega consigo uma força transformadora humana capaz de modificar de forma livre as relações internas de seu sujeito leitor, e ainda suas relações com o mundo e com o próximo. Não é por acaso que a raiz etimológica latina de ambas as palavras, literatura e liberdade, seja liber. Logo, a literatura é capaz de estimular uma liberdade inalcançável com a mera vivência cotidiana humana. É essa liberdade de construção do eu, e consequentemente do nós, que acreditamos ser direito de todos os seres humanos no campo psíquico e no campo social.

\section{O DIREITO À LITERATURA E SUA RELAÇÃO COM O DIREITO À EDUCAÇÃo E À CULTURA}

$\mathrm{O}$ direito à literatura se relaciona diretamente com outros direitos humanos, justamente em decorrência de sua universalidade e interdependência. Dentre eles podemos citar o direito à educação e à cultura.

Sabemos que a educação é peça fundamental no pleno desenvolvimento da personalidade humana, além de requisito indispensável ao exercício da cidadania. "Com ela, o indivíduo compreende o alcance de suas liberdades, a forma de exercício de seus direitos e a importância de seus deveres, permitindo a sua integração em uma democracia efetivamente participativa" (Cavalcante, 2014, p. 252). Assim, tanto a educação como a literatura podem ser consideradas parcelas 
indissociáveis de uma existência digna, integrando o denominado mínimo existencial.

A literatura tem sido um instrumento poderoso de instrução e educação, entrando nos currículos, sendo proposta a cada um como equipamento intelectual e afetivo. Os valores que a sociedade preconiza, ou os que considera prejudiciais, estão presentes nas diversas manifestações da ficção, da poesia e da ação dramática. A literatura confirma e nega, propõe e denuncia, apoia e combate, fornecendo a possibilidade de vivermos dialeticamente os problemas (Candido, 1995, s.p.)

O direito à educação está previsto no artigo $6^{\circ}$ da Constituição, integrando o rol dos direitos sociais. "No entanto, a educação, não obstante considerada um direito social, é imprescindível à salvaguarda de um direito que, sob um prisma lógico-evolutivo o antecede na formação do Estado de Direito: a liberdade" (Cavalcante, 2014, p. 258). Essa liberdade, proveniente da emancipação decorrente da leitura e do educar, está associada à forma digna de vivência do indivíduo, ou seja, diretamente ligada ao direito à vida e ao direito à liberdade, ambos direitos fundamentais assegurados no artigo $5^{\mathrm{O}}$ do texto constitucional.

Dessa forma, visualizamos o tratamento constitucional dado à literatura, uma vez que, como sustentamos até aqui, é instrumento de grande potência para o desenvolvimento de sensibilidades fundamentais para constituição de sujeitos de cidadania. Se, nos termos do parágrafo $2^{\mathrm{O}}$ do artigo $5^{\mathrm{o}}$ da Constituição, está anunciado que os direitos e garantias fundamentais positivados não excluem outros decorrentes do regime democrático e de tratados internacionais, e estando evidente a interdependência entre a literatura e a educação para o pleno desenvolvimento da pessoa e para o exercício da cidadania e o desenvolvimento, não há como negar que a literatura possui todas as características de um direito humano.

Na educação, a literatura influencia a formação de profissionais das mais diversas áreas de atuação, em especial a do jurista, aqui destacado em decorrência de sua ligação com o desenvolvimento do presente trabalho, de sua relação com o Direito que é criado, interpretado e aplicado por e para pessoas concretas. Nessa linha, afirmamos a literatura como instrumento demolidor de barreiras rígidas do Direito abstraído do mundo da vida. 
A ampliação de uma metodologia jurídica que seja menos tecnicista, menos racionalista e menos positivista baseia-se no resgate e na descoberta da humanidade do jurista através da literatura, justamente por levar os sujeitos a uma reflexão dos valores essenciais da humanidade. Além disso, a literatura se mostra relevante na formação do indivíduo como jurista e no decorrer de sua atuação profissional em razão de o direito ser uma ciência humana, voltada aos problemas humanos, que visa e lida diretamente com o ser humano, e que, dessa forma, necessita de uma compreensão mais realista de seu objeto central.

A literatura pode servir para a construção de uma ponte
entre a esfera teórica e a prática do discurso jurídico e,
até mesmo, mais do que isso: como um instrumento
pedagógico capaz de conscientizar a sociedade da
existência factível de direitos fundamentais (Santos;
Treméa, 2018, p. 162).

É através dos diálogos entre literatura e direito, entre as concretudes de personagens e histórias literárias com institutos e práticas jurídicos, que a emancipação do jurista se faz possível. A literatura tem o condão de humanizar o indivíduo leitor, mas, mais do que isso, tem o poder de humanizar o próprio direito, em consequência de sua capacidade de transcender a linguagem e transformá-la em sentido metafórico, artístico, sensível e belo.

A título de exemplo da relação positiva existente entre direito e literatura, podemos citar a obra espanhola Dom Quixote e como suas leituras contribuem para essa emancipação do jurista ${ }^{11}$. A respeito dessa última, Fachin (2017) afirma que os diálogos com Quixote conferem concretude possível aos direitos humanos, descortinando-se uma utopia capaz de transformá-los em uma dimensão palpável da realidade, já que:

O discurso literário é mais diverso, complexo, heterodoxo e imaginativo - o que lhe permite maior plasticidade, sensibilidade e atenção à realidade; ingredientes dos quais o direito precisa para se comprometer com a realidade daqueles a quem pretende tutelar. A literatura oferece ao direito um vasto repertório de observação das relações humanas sociais, bem como traz liberdade ao

11 Para compreender a fundo essa temática, sugerimos a leitura dos artigos Utopia quixotesca dos direitos humanos, de Melina Girardi Fachin (2017), e Interdisciplinaridade na formação da sensibilidade humanística do jurista e a estereotipação do positivismo e do jusnaturalismo na obra "Os miseráveis", de France Ferrari Camargo dos Santos e Elizângela Treméa (2018). 
direito reiteradamente desconstruindo os formalismos da estrutura jurídica (2017, p. 154).

Essas associações, propiciadas pela leitura do texto literário, despertam no leitor-jurista reflexões acerca da humanidade (ou falta de) da ciência jurídica. Ou seja, juntamente com seu papel humanizador pessoal, psicológico e social, a literatura também atua na formação jurídica-crítica de um profissional, humanizando-o de forma a sensibilizá-lo para a complexidade da vida humana e de seus conflitos sociais.

A mesma conclusão extraímos da análise da relação entre literatura e cultura. Como vimos, os direitos culturais são parte integrante dos direitos humanos, mas, atualmente, os direitos culturais sofrem diversas limitações em razão de políticas públicas ineficazes ou inexistentes. Tomando o texto literário, objeto central da literatura, como um bem cultural, justamente por seu caráter artístico e formador da identidade, o direito à literatura dialoga diretamente com os direitos culturais e, portanto, com os direitos humanos.

A Constituição Federal, no artigo 215, garante o acesso à cultura nos seguintes termos:

Art. 215. O Estado garantirá a todos o pleno exercício dos direitos culturais e acesso às fontes da cultura nacional, e apoiará e incentivará a valorização e a difusão das manifestações culturais. $\S 10^{\circ} \mathrm{O}$ Estado protegerá as manifestações das culturas populares, indígenas e afrobrasileiras, e das de outros grupos participantes do processo civilizatório nacional. $\S 2 .^{\circ}$ A lei disporá sobre a fixação de datas comemorativas de alta significação para os diferentes segmentos étnicos nacionais. $3^{0} \mathrm{~A}$ lei estabelecerá o Plano Nacional de Cultura, de duração plurianual, visando ao desenvolvimento cultural do País e à integração das ações do poder público que conduzem à: I - defesa e valorização do patrimônio cultural brasileiro; II - produção, promoção e difusão de bens culturais; III formação de pessoal qualificado para a gestão da cultura em suas múltiplas dimensões; IV - democratização do acesso aos bens de cultura; V - valorização da diversidade étnica e regional.

Sendo a literatura fonte de cultura, medidas são necessárias para garantir do Estado o apoio à literatura, tanto no interior das comunidades que a produzem, quanto fora delas. Nesse sentido, ainda vale referência ao Plano Nacional de Cultura (PNC), instituído pela Lei 12.343/10, tendo por objetivo planejar e implementar políticas públicas de longo prazo (até 
2020) voltadas à proteção e promoção da diversidade cultural brasileira. Dentre suas estratégias e ações, inclui-se a seguinte:

1.5.4 Estabelecer programas específicos para setores culturais, principalmente para artes visuais, música, artes cênicas, literatura, audiovisual, patrimônio, museus e diversidade cultural, garantindo percentuais equilibrados de alocação de recursos em cada uma das políticas setoriais (Brasil, 2007, s.p.).

Internacionalmente os direitos culturais são encontrados em diversas fontes, como a Declaração Universal dos Direitos Humanos (1948), o Pacto Internacional dos Direitos Econômicos, Sociais e Culturais (1966) e o Pacto Internacional dos Direitos Civis (1966), dentre tantos outros documentos internacionais de relevo, como é o caso da Declaração Universal sobre a Diversidade Cultural. Esta Declaração traz em seu artigo $1^{\circ}$ a ideia de que a diversidade cultural é, para o gênero humano, tão necessária como a diversidade biológica é para a natureza, e ainda afirma, em seu artigo $3^{\circ}$, que essa diversidade "é uma das fontes do desenvolvimento, entendido não somente em termos de crescimento econômico, mas também como meio de acesso a uma existência intelectual, afetiva, moral e espiritual” (UNESCO, 2001, s.p.), sendo sua defesa um imperativo ético, inseparável do respeito à dignidade humana.

As Linhas Gerais de um Plano de Ação para a Aplicação da Declaração Universal da UNESCO sobre a Diversidade Cultural estabelecem que os Estados Membros se comprometem a tomar todas as medidas cabíveis para difundir a Declaração, objetivando aplicá-la e realizar alguns objetivos elencados. A respeito deles, damos destaque ao item 4, que afirma ser necessário "avançar na compreensão e no esclarecimento do conteúdo dos direitos culturais, considerados como parte integrante dos direitos humanos" (UNESCO, 2001, s.p.). Sendo a literatura indissociável da cultura, justamente por integrar o que seria seu conteúdo, o direito à literatura também será considerado como parte integrante dos direitos humanos.

Ainda no campo do direito internacional, é de relevância citar a Convenção sobre Proteção e Promoção da Diversidade das Expressões Culturais, promulgada no Brasil em 2007 pelo Decreto $n^{0}$ 6.177. Muitos são os seus objetivos, mas voltamos uma atenção maior para dois deles: proteger e promover a diversidade das expressões culturais e criar 
condições para que as culturas floresçam e interajam livremente em benefício mútuo.

Para atingir o primeiro objetivo acima elencado, a Convenção determina, em seu artigo 7, medidas como a criação de um ambiente que encoraje indivíduos e grupos sociais a "criar, produzir, difundir, distribuir suas próprias expressões culturais, e a elas ter acesso" (UNESCO, 2005, s.p.), dando atenção diferenciada às necessidades especiais da mulher, de outros grupos sociais, de minorias e povos indígenas. O Brasil, como signatário desse tratado, se compromete com essa determinação. E mais, ao trazer em seu artigo 4 a definição de diversidade cultural como uma multiplicidade de formas pelas quais as culturas dos grupos e sociedades encontram sua expressão - que se manifesta através de diferentes modos de criação, produção, distribuição e fruição das expressões culturais -, o Estado brasileiro assume o compromisso de fazer valer tais palavras e, sendo a criação e fruição literária expressão cultural de um povo, a literatura mais uma vez é afirmada como um direito humano garantido no ordenamento jurídico vigente.

Aliás, sustentando o que afirmamos anteriormente a respeito da relação existente entre direito à literatura, direito à educação e direito à cultura, o artigo 10 da Convenção em questão afirma que as partes signatárias devem propiciar e desenvolver a "compreensão da importância da proteção e promoção da diversidade das expressões culturais, por intermédio, entre outros, de programas de educação e maior sensibilização do público" (UNESCO, 2005, s.p.). Vemos, portanto, a indissociabilidade de tais direitos, tendo em vista que a educação é um meio pelo qual a cultura se constrói e se propaga, além de ser responsável pela alfabetização dos indivíduos e sua inserção no mundo da linguagem e da literatura, logo autor e leitor, sujeitos ativo e passivo da vida literária.

\section{CONSIDERAÇÕES FINAIS}

A literatura traz em si diversas funções e é capaz de despertar no leitor inquietações de cunho social, político, ideológico, libertador e catártico. Como vimos, justamente por seu caráter humanizador, ela é um direito humano e deve ser assegurado como tal. Seja na esfera pessoal - no olhar que o leitor faz de si mesmo -, seja na psicológica - no alívio de suas 
pulsões -, ou ainda na social - como o leitor passa a enxergar o outro na sociedade e em sua profissão -, a literatura influencia diretamente na construção, na descoberta e na evolução do ser. Logo, o acesso à literatura associa-se diretamente ao direito à vida digna, à liberdade, à educação, à arte e à cultura, dentre tantos outros direitos que garantem a dignidade da pessoa humana.

Em razão disso, a literatura, como bem incompressível, assegura a sobrevivência digna e a integridade espiritual do ser, devendo, desse modo, ser tratada como direito humano. Finalmente, buscando exemplificar e propiciar no leitor do presente trabalho algumas das transformações proporcionadas pela literatura que citamos aqui, transcrevemos um trecho da obra Os miseráveis:

Enquanto, por efeito de leis e costumes, houver proscrição social, forçando a existência, em plena civilização, de verdadeiros infernos, e desvirtuando, por humana fatalidade, um destino por natureza divino; enquanto os três problemas do século - a degradação do homem pelo proletariado, a prostituição da mulher pela fome, e a atrofia da criança pela ignorância - não forem resolvidos; enquanto houver lugares onde seja possível a asfixia social; em outras palavras, e de um ponto de vista mais amplo ainda, enquanto sobre a terra houver ignorância e miséria, livros como este não serão inúteis (2012, p. 27).

Realmente, as dificuldades enfrentadas pela sociedade parisiense do século XIX ainda se fazem presentes na sociedade brasileira atual, mesmo que em intensidade e maneiras diferentes; o que nos mostra que o ser humano ainda tem muito a evoluir a respeito de sua própria condição como tal e de seu olhar sobre o outro. Sendo a literatura atemporal, os diversos olhares lançados a ela e suas leituras e releituras contribuem para a emancipação e evolução subjetiva e social, mesmo que lentamente. Por fim, a literatura deve ser valorizada e deve ser vista como é: um direito humano. Pois é só através das lentes emancipatórias da literatura que o ser humano atingirá sua essência: sua própria humanidade.

\section{REFERÊNCIAS}

ADORNO, Theodor. Indústria cultural e sociedade. São Paulo: Paz e terra, 2002.

ADORNO, T. W. Educação e Emancipação. Trad. de Wolfgang Leo Maar.. Rio de Janeiro: Paz e Terra, 1995 
ANDRADE, J. C. V. Os direitos fundamentais na Constituição de 1976. 2. ed. Coimbra: Almedina, 2001.

ASSEMBLEIA GERAL DA ONU (1948). Declaração Universal dos Direitos Humanos (217 [III] A). Paris.

BRASIL. Ministério da Educação. Ministério da Justiça. Comitê Nacional de Educação em Direitos Humanos. Plano Nacional de Educação em Direitos Humanos. Brasília: Secretaria Especial dos Direitos Humanos; UNESCO, 2007.

CANDIDO, Antonio. O direito à literatura. In: CANDIDO, Antonio. Vários escritos. São Paulo: Duas cidades, 1995. p. 253-263.

CAVALCANTE, José Estenio Raulino. Direitos culturais e direitos humanos: uma leitura à luz dos tratados internacionais e da constituição federal. Themis -Revista da Esmec, v. 12, p. 243-267, 2014.

COMPARATO, Fábio Konder. Fundamento dos Direitos Humanos. Instituto de Estudos Avançados da USP, 1997. Disponível em: http://www.iea.usp.br/publicacoes/textos/comparatodireitoshumanos.pdf. Acesso em: 30 mar. 2019.

EAGLETON, Terry. O que é literatura? In: EAGLETON, Terry. Teoria da literatura: uma introdução. 6. ed. São Paulo: Martins Fontes, 2006. p. 125.

FACHIN, Melina Girardi. Utopia quixotesca dos direitos humanos. Anamorphosis - Revista Internacional de Direito e Literatura, Porto Alegre, RDL, v. 3, n. 1, p. 153-169, jan.-jun. 2017. Doi: http://dx.doi.org/10.21119/anamps.31.153-169.

FIGUEIREDO. D.; FEITOZA, R.; CARVALHO, M. A arte como instrumento de sublimação das pulsões. Encontro -Revista de psicologia, v. 15, n. 23, p. 49-58, 2012.

FILIPOUSKI, Ana Mariza Ribeiro. Para que ler literatura na escola? In: FILIPOUSKI, Ana Mariza R.; SCHAFFER, Neiva Otero; MARCHI, Diana Maria. Teorias e fazeres na escola em mudança. Porto Alegre: Ed. da UFRGS, 2005. p. 223-228.

FLORES, J. H. Direitos Humanos, interculturalidade e racionalidade de resistência. Sequência (UFSC), v. 23, n. 44, p. 09-29, 2002.

FREUD, Sigmund. O estranho. In: FREUD, Sigmund. Edição standard brasileira das obras psicológicas completas de Sigmund Freud; vol. XVII. Rio de Janeiro: Imago, 2010. p. 138-160.

FRY, Paul H. Theory of literature. Connecticut: Yale University Press. 2012.

HOWARTH, Caroline. A social representation is not a quiet thing: Exploring the critical potential of social representations theory. British Journal of Psychology, v. 45, p. 65-86, 2006.

HUGO, Victor. Os miseráveis. Trad. de Frederico Ozanam Pessoa de Barros. São Paulo: Cosac Naify, 2012. 
KANT, Immanuel. Resposta à pergunta: que é o esclarecimento? In: KANT, Immanuel. Kant textos seletos. Petrópolis: Vozes, 1985 . p. 101-117.

MENDES, Eliana Rodrigues Pereira. Pulsão e sublimação: trajetória do conceito, possibilidades e limites. Revista Reverso, Belo Horizonte, ano 33, n. 62, p. 55-68, 2011.

MORAES, Isabella Lígia. A literatura e seu poder de resgate da totalidade humana. Darandina Revisteletrônica - UFJF, 5. ed., artigo 11, 2010.

NUNES, Diogo César. (Im)possível experiência: literatura e alteridade, teoria crítica e ficção científica. Revista eletrônica literatura e autoritarismo, n. 22, p. 4-18. 2013.

NUNOMURA, Eduardo. Com retaliações e esvaziamentos, Bolsonaro asfixia produção cultural. Carta capital. Disponível em: https://www.cartacapital.com.br/cultura/com-retaliacoes-eesvaziamentos-bolsonaro-asfixia-producao-cultural/. Acesso em: 30 mar. 2019.

PESAVENTO, Sandra Jatahy. Relação entre história e literatura e representação das identidades urbanas no Brasil (séculos XIX e XX). Anos 90 - Revista do Programa de Pós-Graduação em História da Universidade Federal do Rio Grande do Sul, v. 3, n. 4, p. 115-127, 1995.

SALDAÑA, Paulo. Na mira de Bolsonaro, obra de Paulo Freire é pilar de escolas de elite. Folha de São Paulo. Disponível em: https://www1.folha.uol.com.br/educacao/2019/o1/na-mira-de-bolsonaroobra-de-paulo-freire-e-pilar-de-escolas-de-elite.shtml. Acesso em: 30 mar. 2019.

SANTOS, France Ferrari Camargo; TREMÉA, Elizângela. Interdisciplinaridade na formação da sensibilidade humanística do jurista e a estereotipação do positivismo e do jusnaturalismo na obra "Os miseráveis". Anamorphosis - Revista Internacional de Direito e Literatura, Porto Alegre, RDL, v. 4, n. 1, p. 159-186, jan.-jun. 2018. DOI: http://dx.doi.org/10.21119/anamps.41.159-186.

UNESCO. Declaração Universal sobre a Diversidade Cultural. $31^{\mathrm{a}}$. Sessão da Conferência Geral da UNESCO. Paris, 2 novembro 2001. Disponível em: http://www.unesco.org/new/fileadmin/MULTIMEDIA/HQ/CLT/diversity Lpdf/declaration cultural diversity pt.pdf. Acesso em: 30 mar. 2019.

UNESCO. Convenção sobre a Proteção e Promoção da Diversidade das Expressões Culturais. Paris, 20 de outubro de 2005. Disponível em: https://unesdoc.unesco.org/ark:/48223/pfoo00149742?posInSet=10\&que ryId=N-EXPLORE-497a3a1a-6cea-4127-bo5a-14d13fe7e257. Acesso em: 30 mar. 2019.

Idioma original: Português

Recebido: 18/12/18

Aceito: 28/03/19 